\title{
ENTRE PEÑAS, BARES, PUBS Y DISCOTECAS. CIRCUITOS JUVENILES EN LA CIUDAD DE CÓRDOBA DURANTE LA DÉCADA DE 1980
}

\author{
María Sol BRUNO*
}

\section{Resumen}

A lo largo de este artículo trazamos una cartografía del pasado reciente en la ciudad de Córdoba-Argentina. Describimos y analizamos circuitos juveniles a partir de un conjunto de locaciones mercantilizadas que funcionaban como espacios de distribución de ciertas músicas. Exploramos la demarcación de rutas de lo que delimitamos como "mundo de la canción urbana" que se vinculaban con una serie de clasificaciones estético musicales. Palabras Clave: Estudios Sociales de la Música, Juventud, Historia Cultural, Córdoba, Argentina

\begin{abstract}
Abstrac
In this article we draw a recent past cartography in Córdoba City- Argentina. We describe and analyze youth circuits based on some commercial spaces where some music's sounds. We explore routes of, we called, "urban songs word" linked with some esthetic music's classification.
\end{abstract}

Key words: Social Studies of Music, Youth, Cultural History, Córdoba, Argentina

\section{Résumé}

Tout au long de cet article nous avons tracé une cartographie du passé récent à la ville de Córdoba-Argentine. Nous avons décrit et analysé des circuits aux jeunes à partir d'un ensemble des lieux mercantilisés, lesquels fonctionnaient comme des espaces de distribution de certaines musiques. Nous avons étudié la démarcation des routes de ce que nous avons délimité comme "monde de la chanson urbaine », qui étaient associées à une série de classifications esthétiques-musicaux.

Mots clés : Études Sociaux de la Musique, Jeunesse, Histoire Culturelle, Córdoba, Argentine

*Centro de Investigaciones de la Facultad de Filosofía y Humanidades de la Universidad Nacional de Córdoba (CIFFyH- UNC). 
Los lugares de teatro son mapas de las culturas a las que pertenecen

En la ciudad de Córdoba durante las noches de la década de 1980, y a pesar de las restricciones que estableció el gobierno dictatorial iniciado el 24 de marzo de 1976, un conjunto de jóvenes se encontraban en locales comerciales para disfrutar de sus músicas y artistas preferidos. Las chicas y los chicos, en su mayoría estudiantes de carreras de la Universidad Nacional de Córdoba eran oyentes/productores de diferentes músicas. En nuestra pesquisa de doctorado estudiamos un mundo de arte que se componía de diferentes escenas musicales que propiciaban la circulación de aquellos bienes culturales.

En este artículo en particular nos detenemos en espacios de distribución de lo que hemos delimitado como "mundo de la canción urbana". En este sentido, exploramos la demarcación de rutas musicales a lo largo de la trama urbana. En nuestro trabajo de campo construimos clasificaciones estético musicales que estaban íntimamente relacionadas con el trazado de circuitos juveniles. En este texto exploramos locales comerciales de capacidad variable pero limitada a 200 personas como máximo, y que abrían con una frecuencia semanal durante el horario nocturno.

\section{Un mundo de arte con rutas y circuitos}

El horizonte musical de la ciudad de los años ochenta trasciende ampliamente a este texto. En la pesquisa que efectuamos como parte de la tesis de doctorado hallamos una extensa red de producciones musicales que no exploramos en su totalidad. Como estrategia metodológica y de delimitación del objeto empírico acotamos una red de relaciones (Becker, 2008) que posibilitaba la producción musical a la cual llamamos "mundo de la canción urbana". Aquel mundo musical era variado en estilos y géneros, para lo cual optamos por diferenciar tres escenas (Bennett \& Peterson, 2004; Straw, 1972) a las cuales correspondían ciertas rutas y circuitos de distribución.

Dos escenas estaban conformadas por artistas abocados a la producción de canciones que tenían letras y músicas. Por un lado, distinguimos una escena de trovadores comprometidos. ${ }^{1}$ En sus canciones, los artistas visibilizaban temáticas vinculadas a posiciones partidarias que se relacionaban con reivindicaciones de organizaciones políticas de izquierda. Se trataba de letras con contenido social que alentaban la

\footnotetext{
${ }^{1}$ Utilizamos itálica para referirnos a los términos de nuestros entrevistados y fuentes documentales. Cabe aclarar que en este artículo presentamos fragmentos de nuestra tesis de doctorado en Ciencias Antropológicas (FFyH- UNC) titulada De "Aguas de la Cañada" a "Nada en la Cañada". Análisis de un mundo de canción urbana en la Córdoba de 1980, dirigida por el Dr. Gustavo Blázquez. Para este texto en particular tomamos algunos datos que construimos en entrevistas biográficamente centradas, fuentes documentales (diarios de la época, archivos personales de los entrevistados, libros alusivos que escribieron los interlocutores) y notas de campo.
} 
transformación del sistema imperante a favor de una mayor distribución de la riqueza. Quienes consumían y producían estas canciones tenían una participación, o al menos ciertas vinculaciones, con organizaciones políticas de la época, ya sea estudiantiles o partidarias. Estos jóvenes se reconocían a sí mismos como comprometidos o psicobolches.

Si bien en este texto en particular no discutimos las categorías ni juicios estéticos (Frith, 2014) a partir de las cuales los entrevistados se distinguían uno de otros, cabe considerar que el tránsito por ciertos circuitos de distribución de la música, junto a otros consumos culturales, se complementaba y actuaba en conjunto con formas de vivenciar la política. Estos jóvenes, que si bien pueden haber tenido puntos en común por aquellos estudiados por historiadores en la ciudad de Buenos de Aires (Manzano, 2018) tenían una particularidad local a partir de la cual esbozaron sus propias antinomias y experiencias en la ciudad de Córdoba (Bruno, 2019).

Otra escena de trovadores se integraba de jóvenes de edades biológicas menores a los jóvenes comprometidos. Estas personas se auto identificaron como desinteresados de la política, aunque ello no implicaba una despolitización de sus producciones. Ellos auto adscribieron a la categoría de anarquistas para diferenciarse de otros jóvenes que ellos identificaban como psicobolches. Tanto productores como sus consumidores buscaban deliberadamente distinguirse política y estéticamente de la escena de trovadores comprometidos/psicobolches. Mientras en la escena de trovadores comprometidos las políticas de censura dictatoriales aparecían de manera intermitente para señalar la peligrosidad y oposición a los intereses del régimen dictatorial, en la escena de los trovadores anarquistas no irrumpieron estas intervenciones estatales, en parte porque aquellas músicas sonaban ya en tiempos democráticos. ${ }^{2}$

La tercera escena que identificamos fue contemporánea temporalmente con las escenas de los trovadores -comprometidos y anarquistas-, y en ocasiones compartían espacios comunes. Las sonoridades que circulaban aquí tenían la particularidad de ser producciones, casi exclusivamente, instrumentales. Los estilos sonoros que predominaban fueron el rock y el jazz.

Las escenas eran ensamblajes que permitían a los artistas mostrar y producir sus obras, y a sus públicos conocerlas y disfrutarlas. Los espacios de distribución era una instancia que permitía este encuentro. De aquí que en este artículo en particular nos preguntamos ¿dónde sonaban las músicas del mundo de la canción urbana en la trama de la ciudad de Córdoba?

Richard Schechner (2000) llama la atención sobre cómo las sociedades construyen circuitos y rutas en el espacio/tiempo. En este sentido nos invita a reflexionar que los

\footnotetext{
${ }^{2}$ Durante la última dictadura militar las políticas culturales estuvieron al servicio del imaginario gubernativo que postulaba la existencia de una guerra integral contra el comunismo que no sólo se combatía por los frentes materiales sino también espirituales. En sintonía con esto, el estado dictatorial tuvo dos fases de acción: la persecución, censura y represión de lo que reconocían como subversión cultural y; por otro lado, la producción y difusión de una cultura oficial que promovían los auténticos valores de la civilización occidental y cristiana. La política cultural no sólo se encargó de censurar y destruir, sino promover y hasta premiar algunas obras disruptivas en el campo de la plástica (González, 2012).
} 
movimientos no son azarosos, y cómo a través de ellos las personas asocian dichos consumos a categorías clasificatorias en el mundo social al cual pertenecen (Douglas \& Isherwood, 1990). Planteamos como hipótesis que la diferenciación de estos circuitos asociaba a las personas con ciertas categorías estético-musicales que las diferenciaba entre sí. Aunque de manera móvil y situacional, los jóvenes transitaban los espacios, y en su asistir frecuente, mediante la performance de la escucha construían una subjetividad (Hennion, 2012).

Schechner utiliza dos categorías que nos resultan útiles para organizar esta hipótesis de trabajo. Por un lado, plantea el modelo de erupción como una performance teatral con sucesos calientes y fríos en el cual las personas circulan. A partir de este modelo analizamos a las performances musicales dentro de las locaciones comerciales. Simultáneamente, y a parir de las sugerencias de este autor, nos detenemos en los procesos de escritura que transformaron los espacios en lugares. Ya sea mediante decoración específica, disposición de mobiliario, luces o sonidos, exploramos cómo los diferentes sitios nocturnos se demarcaban en la trama urbana como espacios de divertimento asociados a circuitos juveniles específicos. Por otro lado, Shechner nos habla de procesiones para referirse a peregrinaciones con una trayectoria específica en la cual diferentes espectadores se reúnen y se realizan performance en lugares designados. En este texto analizamos, a partir de la trayectoria de los entrevistados, sus tránsitos dentro de la trama urbana de la ciudad vinculados a los consumos musicales.

Dentro de la geografía del consumo de los jóvenes que fueron objeto de nuestra investigación distinguimos una clasificación de locaciones donde era posible el consumo y la producción de músicas. Distinguimos peñas, bares, pubs y discotecas; entre las cuales analizamos casos emblemáticos. Como variables de análisis nos preguntamos por la construcción de sus carteleras artísticas, las performances que allí acontecían, los consumos de alimentos y bebidas, la concurrencia de públicos habituales y los usos del espacio. A lo largo del texto estaremos atentas a una serie de interrogantes como ¿qué categorías clasificatorias operaban en la descripción de estos circuitos? ¿Cómo incidían en formas de hacer juventudes específicas? ¿Cómo historizar estas cartografías urbanas durante los ' 80 ?

\section{Peñas}

Durante el periodo que estudiamos, y en la ciudad de Córdoba, detectamos un circuito de locales comerciales que los interlocutores coincidían en denominar peñas. Estos espacios de entretenimiento no son exclusivos de la ciudad ni de la década de 1980, emergieron durante la década del 1930 y tuvieron su auge en la década del 1960, sobre todo con la visibilidad que adquirió en la capital del país y la llegada de lo que se representaba como la música folklórica del "interior" (Pujol, 2011). Las peñas se insertaron dentro de un sistema de consagración del campo del folklore, y se instituyeron como tales entre las décadas de 1940/60 (Díaz, 2009).

Particularmente, en nuestra investigación, nos detuvimos en tres casos emblemáticos a los cuales refirieron nuestros entrevistados, y que se ubicaban a escasos metros de distancia entre sí. Estas peñas tuvieron actividad de manera contemporánea gran parte de 
su existencia, y su ubicación coincidía con un barrio de la ciudad próximo al centro y de gran población estudiantil. Funcionaban en espacios modestos que en general no superaban la capacidad de 100 personas. Se trataba de viejas casonas que no fueron concebidas arquitectónicamente como espacios para la noche, pero que sus gestores acondicionaron para darles un nuevo uso.

TONOS Y TONELES (1973/1993) se emplazó en una vivienda que fue acondicionada por sus gestores. ${ }^{3}$ Dada su escasa capacidad, quienes administraban el comercio decidieron techar su patio para agrandar el espacio. Allí había un árbol de higos que se vio alterado por el reacondicionamiento de su hábitat y se volvió desobediente a los ciclos biológicos de las estaciones. En cuanto a la decoración del espacio, los entrevistados y empresarios de la peña coincidieron en señalar que no se destinaba un presupuesto específico para ello. Sin embargo, el local tenía objetos decorativos que, a partir de fotografías de la época y recuerdo de los entrevistados, pudimos reconstruir. Las paredes estaban adornadas con afiches de artistas admirados por sus gestores y asistentes, un caso especialmente recordado fue la figura de CECILIA TODD. ${ }^{4}$ También colgaban de las paredes accesorios concernientes al uso doméstico de caballos como estribos, cinchas, herraduras y una rueda de carreta. La figura equina también se hacía presente a través de las intervenciones de un artista plástico local, Edgardo Moreno Ulloa. El artista dibujaba caballos en los espacios libres de los muros con carbones del asador del patio. Las paredes del local no escatimaban en manchas de humedad y los elementos que las decoraban citaban más al espacio rural que a la ciudad.

La NueVA Trova (1982/1986), fue otra peña que administró uno de los dueños de ToNOS Y TONELES. Aunque con una estética similar que atraía a los mismos públicos, la NUEVA TROVA tenía una estructura edilicia con mejores condiciones arquitectónicas. No había manchas de humedad en sus paredes, contaba con una decoración especialmente concebida para el espacio y diseñada por un escenógrafo, y a diferencia de otros locales que analizamos contaba con un escenario sobre elevado.

El CARILlón (1980/1986) también funcionaba en una casa alquilada que fue refaccionada para su funcionamiento. Se trataba de lo que en la jerga popular se conoce como "casa chorizo", pues tenía una disposición arquitectónica con habitaciones contiguas conectadas por un pasillo. Su principal gestor, Rodolfo Trabalón, hizo voltear algunas paredes a los fines de integrar la casa en un espacio común, de lo cual resultó un sitio angosto y largo. Era un ambiente de poca luz, cuyas paredes estaban pintadas de blanco, con una terminación económica y rústica llamada revoque bolseado. Algunas de ellas fueron dibujadas por dos humoristas gráficos reconocidos del medio: Crist (habitué del espacio) y Roberto Fontanarrosa.

\footnotetext{
${ }^{3}$ Para más datos sobre esta locación en particular ver Bruno (2015)

${ }^{4}$ Cantautora Venezolana de gran aceptación por los jóvenes que asistían a TONOS Y TONELES, en su clasificación estilística fue encasillada dentro del folklore latinomaericano, y también era reconocida por su compromiso político. Durante nuestro trabajo de campo asistimos a la premiación de esta artista por la Universidad Nacional de Córdoba, y a la posterior charla dictada por Todd titulada "Música popular en Venezuela y Latinoamérica" (6 de agosto de 2015, UNC). Durante este evento las autoridades y el público presente, destacaron la importancia de la artista en sus trayectorias juveniles. Al mismo tiempo Todd rememoró anécdotas en la ciudad de Córdoba durante el pasado.
} 
Así como los espacios no fueron espacialmente concebidos para el entretenimiento, quienes estuvieron a cargo de su gestión devinieron en empresarios de la noche a lo largo de aquellas noches de los ochenta. Se trataba de sujetos autopercibidos varones heterosexuales, de edades biológicas similares a los artistas que difundían, que fueron públicos habituales de espacios similares a los que gestionaron cuando eran estudiantes universitarios. Ellos tenían otras profesiones, ya sea porque eran profesionales o participaban de otros oficios para su subsistencia. Esta ligazón con la producción cultural venía dada por sus intereses y aficiones particulares, que desembocaban en deseos y posibilidades concretas de convertirse en gestores de espacios que promovían músicas de sus preferencias. Advertimos que imaginar un local propio requería de una experiencia previa en los mundos de la noche e información del espacio geográfico donde podría instalarse. Aunque los vínculos cooperativos que posibilitaban el funcionamiento de estos espacios se actualizaban con el transcurrir de las noches, era necesario contar con un capital previo que garantizara cierta promoción, artistas y públicos.

Las peñas abrían sus puertas de jueves a domingos a partir de las $22 \mathrm{hs}$. y cerraban durante la madrugada o incluso la mañana siguiente. En estos lugares predominaban las sonoridades de folklore latinoamericano y artistas que describimos como trovadores comprometidos. Esto no impedía la presentación de grupos de rock, de jazz o de tango.

Los artistas provenían de Buenos Aires y otras provincias del país. Artistas locales se presentaban periódicamente, y eran espacios que propiciaron la formación de conjuntos nuevos. Los artistas se encontraban en estos lugares e interpretaban canciones juntos habilitados por los momentos de peña libre. Simultáneamente los gestores de las peñas propiciaban estos contactos ya que funcionaban de intermediarios y en ocasiones facilitaban el espacio del local para momentos de ensayo o contrataban a los artistas para días específicos.

TONOS Y TONELES inició sus actividades sin espectáculos en vivo, según recuerdos de sus asistentes lo que hizo emblemático a este espacio fue la peña libre. La peña libre permitía a los públicos que asistían devenir artistas, pues el local comercial ponía a disposición una guitarra, y en ocasiones un bombo, que circulaban entre los asistentes. Aquellas guitarreadas también se repetían en casas particulares y, como señala Pujol (2011) para el caso de Buenos Aires, constituyeron una práctica que se remontaba a la década de 1960 con el furor del folklore y quizá, para el caso de Córdoba, a una tradición más antigua que se conecta con la vida universitaria de jóvenes de provincias del norte argentino y la bohemia local.

Esta práctica de la peña libre también tenía lugar en El CARILLón, no así en la NuEVA TROVA. Quien administró este espacio tuvo una experiencia previa en TONOS Y TONELES, lo cual lo llevó a privilegiar los espectáculos en vivo para el nuevo local. A criterio de los gestores de estos espacios la peña libre provocaba inconvenientes y hechos violentos, pues quienes asistían ingerían bebidas alcohólicas en exceso y se comportaban de modo agresivo.

Asimismo, cabe aclarar que estas locaciones empezaban su actividad convocando a las personas a la práctica de la peña libre, y cuando lograban notoriedad dentro del circuito juvenil universitario comenzaban a programar espectáculos en vivo e incorporaban una 
entrada mercantilizada. Los espectáculos en vivo no obturaban la posibilidad de la peña libre, pues esta tenía lugar finalizada la performance de los artistas programados.

La cartelera artística era seleccionada en gran parte por los gestores de estos espacios que tejían redes atravesadas por la confianza y recomendaciones que permitieron una programación semanal en sus locales y fuentes de trabajo para los artistas. Los músicos se sometían a ciertas condiciones de ejecución (Becker \& Faulkner, 2011) en los espacios de las peñas, pues elegían un repertorio adecuado y su performance podía llegar a repetirse si tenían convocatoria de públicos y este celebraba su actuación. A los músicos les pagaban los dueños de los locales un porcentaje de las entradas.

La performance de los artistas se realizaba en un escenario que podía o no estar sobre elevado. A veces se recurría a una tarima, o simplemente se colocaban los instrumentos y equipos. El escenario, resultaba de una demarcación espacial realizado con equipos propios de los músicos con cables que convergían en la consola de sonido que reposaba sobre un rincón. Así, el espacio se convertía en un teatro para la performance musical a partir de esta "escritura" del lugar. Esta organización espacial habilitaba un mayor intercambio entre los artistas y sus públicos.

Las peñas destacaban la presencia de los artistas cuando estos desarrollaban su performance, aunque con dispositivos técnicos modestos, pues era poco habitual que el local tuviera una planta de luces con su respectiva consola y técnico iluminador. Lo más usual eran luces blancas que apuntaban hacia el escenario. En el terreno del público predominaba la oscuridad.

Fuera de escenario las peñas disponían de mesas y sillas en las cuales se ubicaban sus asistentes. Estos comercios ofrecían una oferta gastronómica y personal que atendía a sus clientes para tomar y llevar sus pedidos. Las bebidas de consumo más difundido fueron el vino tinto de damajuana y la cerveza. En lo que respecta a los alimentos, eran populares las empanadas de carne, y en ocasiones otras comidas consideradas "típicamente criollas" (Archetti, 1999) como locro, tamales y choripanes. ${ }^{5}$

Como el vino provenía de damajuanas, quien administraba El CARILLón explicó que lo distribuía en botellas de vidrio de medio litro. Este formato habilitaba a sus consumidores dejar las botellas vacías sobre las mesas, así llevaban el control sobre la cantidad de vino que habían ingerido. Mediante la acumulación de botellas vacías grupos de jóvenes construían su fachada (Goffman, 1971) en el espacio del local, y en función de la cuantía se distinguían de otros asistentes.

Los jóvenes habitués de estos espacios acudían con sus amigos o con sus parejas. Una motivación podía ser apreciar un conjunto musical de su preferencia estética, o quizás porque algún artista con el cual tenían vinculación afectiva se presentaba en alguna peña. Los asistentes a los locales se acomodaban en mesas y sillas. Compartían charlas con las personas de la mesa, y al momento de la performance musical hacían silencio y

\footnotetext{
${ }^{5}$ Según recuerdos de nuestros entrevistados el alimento ocupaba un lugar secundario, pues era prioritario el consumo de bebidas, aunque esta fuera de baja calidad. Una de nuestras entrevistadas explicó que ella y sus amigos no acostumbraban comer en la peña porque en general disponían de poco dinero, el cual preferían destinarlo a las bebidas.
} 
permanecían en sus sillas. La escucha atenta sin activación de sus cuerpos que se movieran al ritmo de la música era una convención para el consumo de las músicas. ${ }^{6}$

Esta convención para el consumo de la performance en vivo se replicaba al momento de la peña libre. Si bien aquí no había escenario, quienes interpretaban las canciones eran escuchados atentamente. Las personas permanecían en sus sillas, y su participación se limitaba a cantar las canciones a coro.

Las peñas participaban de un financiamiento y organización autogestiva. Sus gestores promovían las actividades que allí se realizaban sin acudir a los medios de difusión masivos. Los sistemas que permitían difundir las actividades de este espacio se activaban a través de redes de personas conocidas que recomendaban la peña. También entre los gestores y los artistas implicados producían folletería y afiches con información de las presentaciones. Estos últimos no tenían un diseño gráfico de gran despliegue ni una amplia distribución. El trabajo de difusión no era delegado a otras personas, sino que eran los artistas y gestores de la peña, en ocasiones acompañados de amigos o familiares, quienes llevaban adelante esta tarea. Estos sistemas de distribución fueron definidos por los interlocutores como artesanales, y se insertaban en un universo de sentidos de una economía moral (Thompson, 1995) alternativa compartida entre productores y consumidores de estas músicas.

Este modo de concebir la economía llevaba a quienes administraban estos lugares a expresar su desinterés por las ganancias económicas. Tenían poco control sobre las ventas de entradas, bebidas y alimentos. Muchas veces concedían "fiado", una postergación de pago a sus clientes, y no llevaban un registro minucioso del dinero que ingresaba ni de los gastos del local. En palabras de quien gestionó TONOS Y TONELES y la NUEVA TROVA: (...) si, éramos muy desordenados, muy desordenados, absolutamente muy desordenados, no había control de nada. Yo me acuerdo una noche vendimos doscientos cincuenta litros de vino y quinientas empanadas, era una fortuna de guita [dinero]. Yo no tenía ... había meses que no llegaba a fin de mes. Pero, un desastre, era muy, se bancaba [no se le cobraba por sus consumos] a mucha gente, todo mal. Pero bueno, éramos muy jóvenes, a lo mejor por eso escribió toda una historia el boliche ese, si hubiese sido más prolijito hubiésemos andado en auto todos, cosa que ni soñábamos (Entrevista con Acevedo, n. 1950, entrevista realizada en Villa Carlos Paz-Córdoba, Septiembre de 2013)

Esta forma de organización de recursos llevaba a estos empresarios a diseñar estrategias para la retribución monetaria de los artistas. No sólo porque no se les pagaba un cashet previo, y tanto empresarios como artistas participaban juntos de la promoción de sus eventos, sino porque las transacciones monetarias se llevaban a cabo de palabra sin mediar ningún tipo de instrumento legal. Otra característica era que si los artistas provenían de otras ciudades eran alojados en las casas particulares de estos gestores de locales o en viviendas de sus amigos.

Las personas que elegían estos locales comerciales para su esparcimiento, lo hacían de manera periódica y construían un circuito entre las peñas. Esta situación daba como resultado una superposición de públicos entre TONOS Y TONELES, LA NUEVA TROVA y EL

\footnotetext{
${ }^{6}$ Varios de nuestros interlocutores contrastaron su experiencia posterior, más próxima al momento en que realizamos nuestro trabajo de campo, sobre las peñas. Si en estas peñas no se bailaba, las que acontecieron a partir de la década de 1990 sí. Para un análisis en profundidad sobre las peñas contemporáneas en la ciudad de Córdoba consultar Acurso (2016)
} 
CARILlÓN. Eran, en su mayoría, estudiantes universitarios, originarios de la ciudad o de otras provincias que se habían mudado para estudiar en la UNC. También acudían periódicamente poetas, músicos y artistas plásticos.

Los públicos habituales de las peñas también eran militantes políticos de organizaciones de izquierda. El diario La Voz del Interior (LVI, 28/10/2007) en una nota rememorativa de TONOS Y TONELES, planteaba que a este local asistían jóvenes de clase media, generalmente cultos o que pasaban por tales. Según Acevedo, el público de Tonos era de clase media progresista. De estas descripciones podemos advertir que este espacio de esparcimiento pertenecía a sectores medios con un nivel educativo determinado, y con afinidades por las actividades artistas. A su vez nuestros interlocutores destacaron que muchos de estos jóvenes tenían una posición política de izquierda que los hacía progresistas, muchos de ellos conformaban organizaciones y partidos políticos. En cuanto al CARILLÓN, su principal gestor planteó en la entrevista que le realizamos, que muchos de sus asistentes participaban de actividades de militancia política, y utilizaban el espacio como un punto de encuentro durante tiempos dictatoriales.

Simultáneamente, las peñas atraían otros públicos ocasionales que no necesariamente cumplían con estas características. Quienes no eran asistentes habituales eran reconocibles gracias a la construcción de sus fachadas (Goffman, 1971). Según los empresarios de las peñas, los habitués se distinguían por sus arreglos informales y desprolijos en relación a lo que socialmente se esperaba para una salida nocturna. Estos jóvenes no se vestían especialmente, podían ir de ojotas o zapatillas, o con los atuendos que utilizaban para cursar en la universidad.

Estos espacios no estuvieron librados de los mecanismos de control de las fuerzas de seguridad durante el gobierno dictatorial. TONOS Y TONELES sufrió varios allanamientos y razzias policiales en sus noches de actividad. Las fuerzas de seguridad ingresaban al local, se llevaban a los jóvenes allí presentes detenidos hacia una comisaría o al Cabildo de la ciudad. Las personas eran demoradas una noche, o quizás más. Una forma de evadirse de la detención era el pago de coimas a las fuerzas de seguridad. Los gestores de TONOS obsequiaban a los policías de turno una cantidad de vino y empanadas cada noche. Con el transcurrir del tiempo ambas partes construyeron una relación de confianza, los policías se anticipaban a los allanamientos y avisaban a sus gestores. Esta información permitía alertar sobre el potencial peligro a los asistentes de la peña y minimizar riesgos de posibles detenciones permanentes o desapariciones forzadas. ${ }^{7}$

La Nueva Trova también fue blanco de intervenciones, multas y clausuras por los organismos de control estatales. Estos hechos se iniciaron con la apertura del local bajo el gobierno dictatorial pero no se interrumpieron con la institucionalización democrática. Ya en tiempos alfonsinistas los controles estatales estaban a cargo de la Dirección de

\footnotetext{
${ }^{7}$ Cabe destacar que las intervenciones de las fuerzas de seguridad se llevaron a cabo en diversos espacios de esparcimiento juvenil y que no se interrumpieron con la institucionalización democrática. Las estrategias de evasión eran variadas. Sobre algunas escenas de interacción entre varones homosexuales y agentes policiales en la calle puede consultarse Blázquez \& Reches (2017).
} 
Espectáculos Públicos de la Municipalidad de Córdoba. Era habitual que el local fuera multado, clausurado e incluso sufriera amenazas por parte de inspectores. ${ }^{8}$

A diferencia de Tonos y Toneles y la Nueva Trova, el CARILlón nunca sufrió allanamientos ni clausuras. Sin embargo, su gestor recordó un episodio conflictivo con las fuerzas de seguridad, en tiempos dictatoriales, cuando programó la actuación de Armando Tejada Gómez. El ejército se hizo presente en el local un día antes del show, y llevó al empresario de la peña al predio del Tercer Cuerpo del Ejército. Allí sin mediar armas ni acudir a la violencia física le explicaron la gravedad de la presentación de este artista, pues era caratulada como un acto "muy virulento" dentro de la escala de hechos prohibidos. Si el show se realizaba la peña sería suspendida y clausurada. Ante esta situación el dueño del local canceló el espectáculo, aunque Tejada Gómez le expresó su enojo, le planteó que en aquellos tiempos era necesario combatir y que una manera de hacerlo era mantener la actuación en cartelera, el empresario no cambió su decisión.

Las participaciones políticas de muchos de sus asistentes, las músicas que sonaban en este local y las irrupciones periódicas de las fuerzas de seguridad llevaron a describir a las peñas como espacios cargados de cierto grado de politicidad. Esta apreciación resultaba de una escritura en el espacio que transformaba este lugar en una experiencia politizante (Schechner, 2000). Así, las acciones transformaban un local de esparcimiento en un espacio de reconocimiento de un grupo de jóvenes. Las músicas señalaban una adscripción política mediante sus poéticas, el Estado marcaba aquella politicidad mediante sus intervenciones y sus asistentes se autodefinían como psicobolches. Aunque el local no era un espacio destinado a la militancia política posibilitaba un espacio de sociabilidad de jóvenes con ethos y cosmovisiones (Geertz, 1987) afines.

Otra característica que advertimos de estas peñas, era que no se circunscribían exclusivamente al tiempo de la noche ni al espacio donde funcionaban habitualmente. Los aniversarios de estos locales se celebraban especialmente con la presencia de varios artistas y en espacios más amplios como clubes deportivos de la ciudad. En estas peñas también se hacían eventos privados, como cumpleaños y casamientos. Funcionaban como espacios de ensayo de artistas, o incluso como locación para la formación de artistas como fue la Escuela de Músicos LA Colmena. ${ }^{9}$ Además de las performances musicales los espacios de peña propiciaron presentaciones de libros, revistas y concursos de pintura, se dictaban talleres culturales, encuentros corales o cenas de camaradería entre los artistas.

Por otro lado, advertimos que la organización de la gestión de estos locales comercializados se constituía como una tecnología social que tenía efectos en la

\footnotetext{
${ }^{8}$ Desde la perspectiva de Acevedo el nivel de violencia de estas intervenciones no disminuyó con la instauración democrática, muchas veces se ejercía por las mismas personas o con vínculos con personal militar que había ocupado posiciones de poder. Acevedo recordó que en una ocasión recibió una amenaza por un inspector de espectáculos públicos en el patio del local. En el libro de su autoría (Acevedo, Tito (1996). La memoria de los boliches. Córdoba) relató que el sujeto en cuestión lo invitó a salir, le mostró su chaleco anti-bala y un arma calibre 45, bajo el consejo de portarse bien.

${ }^{9}$ LA COLMENA inició sus actividades en el año 1983, con la finalidad concreta de generar un espacio de formación para géneros de música popular. Sus fundadores fueron un grupo de músicos que tocaban frecuentemente en espacios cordobeses y dictaban talleres de formación musical. Ellos tenían un grupo musical del mismo nombre, cuyos integrantes eran José Luis "Pucho" Ponce, Alberto "Turco" Suárez Assar, y Oscar "Pato" Pedano. La institución seguía en funciones al momento de escribir este artículo.
} 
construcción de individuos como varones y mujeres (De Lauretis, 1989). A cada cual, según su rol en el sistema sexo- genérico le correspondía un papel dentro de la dinámica de la noche. Los artistas, empresarios, técnicos y demás personal de apoyo eran varones. Las mujeres pocas veces llegaban a ser artistas o interpretar instrumentos durante el momento de la peña libre.

\section{Bares}

Otros locales mercantilizados que eran transitados por los jóvenes del mundo musical que investigamos eran un conjunto de bares del centro y zonas aledañas. En alguno de ellos había performances musicales "en vivo", en otros no.

Cuando su principal gestor cerró las puertas del CARILLÓN (1986) compró un local en el centro de la ciudad. Se trataba de una vieja pizzería llamada el BAR DE LAS MUSAS, situado en la avenida Vélez Sarsfield 380, al frente del TEATRO DEL LIBERTADOR SAN MARTín. Esta vez, no instalaría allí una peña, sino un bar que bautizó CAFÉ DEL TEATRO.

A pesar que el local comercial tenía abierta sus puertas durante las 24 horas del día, a partir de las 23 hs la convocatoria de asistentes se incrementaba. Los antiguos habitués del CARILLÓN se trasladaron a este nuevo emprendimiento. Desde la perspectiva de su dueño el bar se transformó en un centro cultural, pues en este espacio se reunían integrantes del medio cultural de la ciudad. En EL BAR DEL TEATRO se encontraban periódicamente periodistas, músicos, actores, escritores, pintores y escultores. En este espacio no había espectáculos musicales ni peña libre.

Trabalón abandonó la gestión del bar a comienzos de la década de 1990. Aunque el bar siguió funcionando con el mismo nombre hasta el año 2018, según recuerdos del entrevistado, los consumidores se modificaron. El local dejó de ser habitado por personas vinculadas a la cultura y al mundo de música alternativa de la ciudad. La ausencia de Trabalón tuvo que ver con esta modificación, pues este gestor se constituyó a lo largo de los años en un intermediario que era reconocido entre los artistas porque propiciaba que sus obras se distribuyeran.

A partir de 1983/1984 aparecieron en la escena nocturna de la ciudad una nueva categoría de locales denominados "video bares". Estos espacios tenían la particularidad de proyectar recitales de rock internacional, ofrecían a sus asistentes el consumo de bebidas y alimentos que podían disfrutan mientras miraban y escuchaban atentamente el televisor. Algunos se localizaban en el centro y otros en la zona norte. Si bien no se cobraba una entrada para ingresar, los alimentos y bebidas que se consumían era a mayor precio que en otros bares.

Gracias a estos locales muchos jóvenes tuvieron la oportunidad de conectarse con otras experiencias juveniles a nivel mundial. En lugares como estos pudieron ver el documental WOODSTOCK. THREE DAYS OF PEACE AND MUSIC que registró parte de las experiencias de aquel festival desarrollado en agosto de 1969 o recitales de bandas internacionales que se realizaban en otras partes de mundo y que eran contemporáneos a la vida de estos jóvenes. Estas transmisiones se reproducían en el canal de MTV, que en nuestro país no era posible 
sintonizar por la inexistencia de la tv por cable que llegaría en los inicios de la década de 1990, y que incluso mediando la década instalaría un estudio propio en el país.

\section{Pubs}

Otros espacios de divertimento juvenil eran los pubs. Estos locales abrían sus puertas los fines de semana durante la noche. Muchos tenían paredes especialmente arregladas y una planta de luces con colores que le daban cierto efecto al ambiente. A juicio de nuestros interlocutores la diversidad de colores y una estética especialmente concebida para el espacio era uno de los elementos que los diferenciaba de las peñas. En estos lugares no se consumían alimentos, sólo bebidas alcohólicas. Sus asistentes no cenaban en estos espacios, pues la salida nocturna se efectuaba luego de comer en sus hogares o casas de amigos. La noche de los pubs se iniciaba luego de las $23 \mathrm{hs}$.

En estos locales se presentaban artistas locales y de otras provincias, algunos coincidían con las carteleras artísticas de las peñas. Los conjuntos musicales interpretaban músicas de rock, pop, y jazz. Los entrevistados coincidieron en señalar que las sonoridades que se escuchaban, ya sea grabada o en vivo, no pertenecía al género del folklore.

Los pubs compartían públicos con las peñas, aunque los interlocutores plantearon que en su mayoría no se trataba de las mismas personas. Los asistentes de pubs también eran estudiantes universitarios, sin embargo, la mayoría de ellos no participaban en organizaciones políticas. Los pubs se diferenciaban de las peñas porque no se constituían como espacios politizantes, eran locales que estaban despojados de la cuestión política. Las músicas que aquí se difundían, así como las conversaciones que se habilitaban en el local no tematizaban asuntos referidos a formas de organización del poder, alternativas de gobierno o alguna crítica a las realidades políticas latinoamericanas de la época.

Las músicas se disfrutaban en silencio y quietud. El público se disponía en mesas y sillas. Ya mediando la década de 1980, comenzó a habilitarse la danza como forma de consumo. Muchas veces, luego de la presentación de un conjunto musical se "armaba la pista de baile". Se corrían las mesas y sillas, y mediante música grabada, generalmente de rock internacional, los jóvenes comenzaban a mover sus cuerpos al ritmo de la música.

Los pubs se localizaban en el centro y en la zona norte de la ciudad. Los entrevistados señalaron dos espacios pioneros en este rubro: OJALÁ y Vinicius. ${ }^{10}$ Otro espacio

\footnotetext{
${ }^{10}$ OJALÁ estaba en el centro de la ciudad. Finalizando la década el local pasó a llamarse LA MADRIGUERA, y sus dueños eran músicos que integraron un conjunto local de folklore latinoamericano. Ya en la década de 1990 reabrió sus puertas con el nombre MARÍA MARÍA, y se transformó en un punto neurálgico del rock local under cordobés. VINICIUS se ubicaba en el Cerro de las Rosas y era propiedad de Ernesto Hitt, gestor de discotecas bailables como HAMILTON y LONG CHAMPS (LVI 28/10/2007). Otros pubs que recabamos de nuestro trabajo de campo fueron DoÑa ANASTASIA, GATO JAZZ, EXCEDRO y SigLO XXI. Este último fue un pub localizado en la zona norte de la ciudad, en el Cerro de las Rosas. Su dueño era músico de jazz, la finalidad de este espacio era propiciar lugar para tocar para grupos de ese género. Según testimonios de nuestros entrevistados su dueño disponía de dinero para sustentar este espacio sin necesidad de preocuparse por su rentabilidad. El local tenía un piano propio que en una ocasión fue prestado a Tito Acevedo para que un conjunto local de jazz se presentara en la peña TONOS Y TONELES. Esta cuestión llama la atención sobre la vinculación entre locales comerciales de diferentes circuitos.
} 
mencionado por nuestros entrevistados fue VANGELIS, local que con el transcurrir de los años se transformó en discoteca y cambió su nombre a PAPATHANASSIOU. ${ }^{11}$

El local fue ideado por tres jóvenes oriundos de la localidad serrana de La Falda, quienes se mudaron a la ciudad de Córdoba para iniciar sus carreras universitarias al inicio de la década de 1980; de manera paralela devinieron en empresarios de la noche con la apertura de este local. Uno de ellos fue Marcelo Cáceres (n. 1962), quien particularmente manifestó, en la entrevista que le realizamos, su pasión por la música desde su temprana adolescencia. En este sentido destacamos como los gestores de espacios nocturnos devienen en empresarios motivados por su afición a ciertas músicas. Quienes se ocuparon de la administración de las locaciones nocturnas que constituyeron circuitos en la trama de la ciudad del mundo de la canción urbana llegaron a ellas luego de transitar como jóvenes públicos y con el anhelo de generar nuevos espacios para las músicas que a ellos les gustaba. Todos ellos tenían una profesión previa, o se desempeñaban en otros oficios de manera simultánea para asegurar su subsistencia económica.

Cáceres era amante del rock internacional, y al llegar a la ciudad comenzó a ser reconocido por sus pares por su pasión por la música. Él gastaba cuantiosas sumas de dinero en discos y revistas musicales, muchas de las cuales eran importadas de Europa y EEUU. A diferencia de los otros empresarios de la noche, no transitaba por los espacios de peñas, sino que era habitué de discotecas bailables de la zona norte de la ciudad en las cuales tocaban disc jockey.

VANGELIS abrió sus puertas a fines de 1983, se localizaba en el centro de la ciudad, en la Avenida Hipólito Irigoyen 150. Desde la perspectiva de sus gestores, el local tuvo la intención de irrumpir en la oferta nocturna de la ciudad de Córdoba, buscaba instituirse como un espacio nuevo con otras propuestas de esparcimiento juvenil a las conocidas en la ciudad. Según Cáceres: La escena nocturna de Córdoba era muy de cafetería, de baja luz, de volumen bajo y mucho, que nosotros le decíamos el psicobolche. Mucho cantautor como Milanés, Silvio Rodríguez. O sea, se escuchaba toda esa camada pos Malvinas y mucha música en castellano. Y la situación de la gente era un poco como sumisa digamos (...) no te digo deprimida, pero no había una gran alegría digamos (Entrevista con Cáceres, Córdoba, Marzo de 2015)

Los administradores de VANGELIS se propusieron generar una estética diferente a la que ellos conocían. A la oscuridad y los tonos terrosos de las peñas y bodegones lo remplazaron con abundancia de luz y mobiliario blanco. En VANGELIS la música se escuchaba a alto volumen dificultando las conversaciones de sus asistentes. Aunque había mesas, como la mayoría de los locales nocturnos, estas eran más bajas y quienes concurrían se sentaban en almohadones en el piso y en las altas alfombras dispuestas en el espacio. Aquí tampoco había mozos, como se habituaban en bares, peñas y pubs de la ciudad. Las personas hacían sus pedidos de bebidas en la barra, así como también tenían

\footnotetext{
${ }^{11}$ El nombre hace referencia al tecladista y compositor artista griego Evangelos Odysseas Papathanassiou conocido como Vangelis. Entre sus obras, enmarcadas en géneros como música electrónica, ambient, new age y rock progresivo, se destacan las partituras originales de las películas "Carrozas de fuego" (1981) y "Blade Runner" (1982).
} 
la posibilidad de solicitar música específica. El disc jockey no se disponía en una cabina distanciado de sus públicos, sino en la propia barra del local. ${ }^{12}$

Otra novedad del pub fue la reproducción de videos VHS en estéreo en una pantalla gigante. Esto fue posible gracias a los contactos que Cáceres tenía en el exterior. Amigos que vivían en Miami le grababan programación del canal de cable MTV que luego era editado y seleccionado. En VANGELIS se proyectaban recitales de rock internacional que no era de circulación masiva entre los jóvenes en la ciudad de Córdoba: entonces yo arranqué poniendo B52, poniendo THE CLASH, poniendo THE POLICE, poniendo mucha cosa, new wave. O sea, rompimos el esquema. Y eso fue explosivo, generó...nosotros estamos en un bar pegado del otro, nosotros empezamos, abrimos pensando que iba a ser una especie de pub de media tarde hacia noche, y abrimos con bandejas de vidrio que tenían alfajores (Entrevista con Cáceres)

VANGELIS se constituyó para Cáceres en una irrupción cultural en la vida nocturna juvenil de la ciudad de Córdoba. La diferencia, según este interlocutor, estaba dada no sólo por la estética del espacio sino en la aparición de lo que él definió como alegría. Para él en su local el público tenía una actitud activa y no de pasividad y quietud como en otros espacios de esparcimiento de la época. Quienes asistían al pub no contemplaban las músicas inmóviles y en penumbras, pues la disposición arquitectónica propiciaba que los jóvenes circularan por el espacio, bailaran, conversaran poco por el alto volumen de la música y pudieran observarse los unos a los otros gracias a la luminaria.

Aunque el local no tenía previsto la presentación de conjuntos musicales en vivo, algunos artistas habitués del espacio propusieron a sus gestores esta posibilidad. Si bien las condiciones edilicias eran limitadas para el montaje de un escenario, los dueños tuvieron el suficiente ingenio para reacondicionar el espacio. En un sector sobre elevado al piso tocaban conjuntos musicales locales. Las bandas que ofrecieron su performance aquí se abocaban al rock y al pop mayoritariamente.

VANGELIS fue parte del mapa nocturno cordobés durante cuatro años, hasta que se convirtió en un boliche bailable denominado PAPATHANASSIOU. Esta transformación se derivó de un comportamiento cada vez más frecuente de parte de sus asistentes. Las personas bailaban en el local, práctica que no estaba habilitada por la Municipalidad de Córdoba para la categoría de pubs. Sus gestores decidieron re direccionar el negocio y transformaron al pub en una discoteca en el año 1987.

\section{Discotecas}

Otros espacios de divertimento nocturno juveniles fueron las discotecas bailables. En la ciudad de Córdoba había discotecas en el centro o en lugares alejados, ya sea en localidades cercanas o a las afueras de la ciudad. Para el caso de estas últimas se volvía

\footnotetext{
${ }^{12}$ Nuestros interlocutores detallaron que se vendían tragos con bebida blanca, algunos resultaron novedosos para sus asistentes pues los gestores del local viajaban con periodicidad al exterior y aprendían nuevas combinaciones desconocidas en la ciudad.
} 
casi fundamental contar con movilidad propia. Los boliches fuera de la ciudad se ubicaban en las localidades de Saldán, Carlos Paz o Villa Allende. ${ }^{13}$

Dentro de estos espacios la iluminación era escenográfica, con efectos especiales como bola de espejos, luces estroboscópicas y humo. El disc jockey acompañaba toda esta ingeniería visual con los efectos sonoros. El volumen de la música era alto, había sillones para sentarse y se tomaban cocteles elaborados con bebidas destiladas y frutas como "destornillador" o "primavera" con alcohol. No se bebía vino ni se consumían alimentos. Rodeando a la pista de baile delimitada por elementos arquitectónicos y lumínicos, sus asistentes podían sentarse, compartir charlas y consumir tragos.

Las músicas que sonaban en las discotecas eran grabadas, tocada por un disc jockey o por conjuntos musicales. Los estilos eran variados, predominaban las músicas que nuestros entrevistados identificaron como comerciales por su gran circulación en medios masivos de comunicación, aunque también sonaban músicas alternativas como conjuntos de rock internacional.

En la pista las personas bailaban "sueltas", guiadas por coreografías menos estructuradas que las danzas de pareja como el tango y el folklore. Aunque más "espontáneo", el baile suponía el dominio de determinados "pasos" o articulaciones precisas entre los movimientos rítmicos de los miembros superiores e inferiores. Hacia el final de la noche, la música disminuía su tempo y se tornaba un tanto más meliflua, las luces estroboscópicas dejaban de funcionar y se iniciaban los "lentos", momento en que los bailarines comenzaban a danzar en pareja, siempre heterogenérica, con movimientos bamboleantes.

Los jóvenes asistían a estos espacios con sus novios o novias, o en todo caso con un grupo de amigos mixtos pares, que formaban parejas siempre heterosexuales aunque no tuvieran relaciones amorosas entre ellos. No era habitual que se bailara con desconocidos.

Las discotecas ubicadas en las afueras de la ciudad hacían necesaria la movilidad propia, notamos en el relato de nuestros interlocutores que, quienes tenían la posibilidad de conducir un vehículo eran siempre sujetos varones. Eran ellos quienes pasaban a buscar a sus novias o amigas para salir a bailar. En ocasiones los muchachos se transformaban en tutores de las chicas, eran jóvenes de sexo masculino de mayor edad biológica que ellas al cual los padres delegaban el cuidado de sus hijas. El permiso se negociaba entre los muchachos y los padres de las chicas, quienes decidían el horario de regreso a sus hogares. Según recuerdos de nuestras entrevistadas el tiempo de permanencia en el boliche estaba marcado por una hora de la noche que establecía que a partir de ese momento sólo quedaban en el local aquellas chicas malas. La duración de la noche y el horario de retirada del espacio público al doméstico marcaban una diferencia en cuanto a sus comportamientos que repercutía en la reputación de estas mujeres.

Las discotecas programaban la presentación de bandas de rock locales y de repercusión nacional, se trasformaban en locaciones de recitales. Algunas de ellas, las ubicadas en

\footnotetext{
${ }^{13}$ Estos espacios no fueron estudiados en profundidad pues no eran los lugares que más frecuentaban los jóvenes que investigamos. Cabe destacar que no contamos con investigaciones empíricas sobre las discotecas en la ciudad de Córdoba durante la década de 1980, invitamos a saldar esta vacancia.
} 
lugares céntricos, llevaban adelante esta práctica durante los días de la semana, reservaban los viernes y sábado para las noches bailables. En las noches de música en vivo había estipendio de bebidas alcohólicas, siendo la cerveza la más popular. Si se trataba de artistas locales, eran ellos quienes se encargaban de la promoción del evento y la venta de entradas anticipadas. El dueño del local no cobraba a los artistas un alquiler, pues sacaba ganancia de los intercambios comerciales en las bebidas. A veces había sillas y otras veces no. Las prácticas corporales de sus asistentes oscilaban entre la quietud y la danza.

Los habitués de estos locales comerciales eran jóvenes que nuestros interlocutores definieron como chetos, frente a los cuales ellos buscaban distanciarse y diferenciarse. Los chetos eran jóvenes consumidores de la música pop romántica, y de la música comercial. También eran sujetos muy preocupados por su estética corporal, de aquí su gran interés por el mundo de la moda y por asistir a peluquerías y centros de estética. El término cheto se aplicaba también a los y las jóvenes provenientes de familias con altos ingresos económicos que habitaban elegantes barrios residenciales y quienes, muchas veces, disponían de un automóvil propio y viajaban a Europa o Estados Unidos. ${ }^{14}$

\section{Entre rutas y circuitos}

Las peñas, bares, pubs y discotecas eran locales de divertimento nocturno juvenil con diferentes estéticas y dinámicas, cuya selección de músicas también respondía a gustos y usos disímiles. A lo largo de nuestra pesquisa identificamos que cada uno de estos espacios se correspondían con un circuito específico de las escenas musicales que identificamos. Si bien los jóvenes expresaban una preferencia por ciertos espacios, no impedía una circulación entre los locales comerciales. Durante los relatos y recuerdos de los interlocutores aparecieron diversos tránsitos entre esos mundos de la noche, lo cual nos plantea la necesidad de abordar a los circuitos en movimiento y de modo relacional.

En este sentido, a partir de las herramientas sociológicas de Norbert Elias (1987, 1995) exploramos procesos a partir de los cuales las personas se entrecruzan en relaciones de amistad y enemistad cuya interrelación produce cambios e interrelaciones que si bien no son planificadas racionalmente tampoco resultan arbitrarias. Consideramos derivas particulares y atendemos a sus derivas personológicas y micro territoriales a lo largo de puntos y localizaciones de redes relacionales (Perlonguer, 2000).

Los espacios de las peñas conformaban la escena de trovadores comprometidos, aunque también transitaran por ellas quienes pertenecieron a las escenas de músicos instrumentales y trovadores anarquistas. Estos locales, así como los bares de cafetería, coincidían en su uso de la música: sus asistentes permanecían quietos y en silencio en los momentos de las performances musicales.

\footnotetext{
${ }^{14}$ Esta categorización fue indagada por otros investigadores como Alabarces (1993), Blázquez (2019), Díaz (2005), Manzano (2011, 2018), Lenarduzzi (2012), Pujol (2011; 2005), Semán y Vila (1999). Insistimos en la carencia de investigaciones empíricas sobre estos sujetos en la ciudad de Córdoba en el periodo que estudiamos.
} 
La escritura del espacio que resultaba mediante sonoridades comprometidas les permitía identificarse con valores determinados que daban cuenta de un ethos y cosmovisión que los aglutinaba. Aquellas músicas, a través de la performance, una y otra vez (re)hacía su carácter de jóvenes "políticamente comprometidos" y participantes en el proceso democrático. Las canciones se escuchaban en silencio con su debida "seriedad". El baile y en especial el boliche fueron considerados prácticas y espacios banales incapaces de generar alguna productividad política. De acuerdo con la perspectiva de los entrevistados quienes bailaban, los y las chetas, eran conformistas con el "sistema" y por tanto incapaces de generar disrupciones. La práctica del baile se asociaba a la diversión y alegría. Estos usos de la música, donde lo serio se identificaba con el pensamiento y lo divertido con el cuerpo se remonta a parámetros de la alta cultura europea y estadounidense en el siglo XIX (Frith, 2014). Respondía a un ideal romántico que separaba cuerpo y razón. Lo "cerebral" se asociaba a músicas para escuchar y las sonoridades para bailar resultaban músicas para el cuerpo que requerían el mínimo de actividad cerebral y eran por tanto irreflexivas.

Desde la perspectiva de los anarquistas/panks, las salidas nocturnas en las peñas y bares se caracterizaban por una carencia de alegría y la tranquilidad. Este uso de la música que prefería a los cuerpos quietos fue compartido por estos jóvenes, aunque ellos incorporaron algunas acciones novedosas. Ellos se permitían gritar y cantar las canciones, cultivaron técnicas corporales más osadas para la época como mover las cabezas de arriba hacia abajo y simular tocar con una guitarra imaginaria para fundirse en la mímesis con el artista que estaba en el escenario.

Los pubs, eran en general espacios que preferían los trovadores anarquistas. Para los jóvenes que participaban de esta escena las peñas eran espacios detestados. Ellos acudían a estos locales comerciales en ocasiones excepcionales, porque en el espacio de la peña podían disfrutar de algún artista que admiraban, en general abocado a lo que denominaban rock. Un modo de hacerse presentes era mediante acciones provocativas, acudían a las peñas a bardear o armar quilombo. En ocasiones montaban una fachada que no se correspondía estrictamente al estilo de los psicobolches, pues se vestían totalmente de negro con largos pilotos y con sus cabellos cortados al estilo militar. A veces, no era necesario la construcción de estos arreglos corporales especiales, sólo bastaba un comportamiento poco habitual como sentarse en una de las mesas de las peñas y pedir un champagne para tomar; bebida que era de consumo más frecuente en las discotecas de moda.

Paralelamente, para otros jóvenes, asistir a las peñas y los pubs eran una actividad compatible y posible. Ambos espacios proponían actividades y programaban músicas similares. Mientras que para unos los pubs se constituían en espacios mas chetos y por tanto próximos a las discotecas de moda, para otros eran compatibles con los circuitos de las peñas que transitaban asiduamente. Esta superposición de circuitos entre pubs y peñas era habitual para los jóvenes que participaban de la escena de músicas instrumentales. Las peñas programaban ciclos especiales para este tipo de músicas, y muchos pubs se especializaban en la difusión de estas sonoridades.

En las discotecas, el uso privilegiado de las músicas era la danza. Esta práctica contrastaba con la de otros espacios de divertimento que investigamos, aunque con el avanzar de la 
década los pubs comenzaron a habilitar el baile con mayor frecuencia. Los boliches bailables eran calificados por los interlocutores como lugares exclusivos de jóvenes chetos. Quienes transitaban peñas y recitales de rock entendían que acudir a estos espacios era casi imposible.

Sin embargo, había excepciones que permitían que amantes de las peñas y pubs también fueran públicos de discotecas. Dentro de los jóvenes que entrevistamos dimos con varios casos en los cuales se combinaban estos espacios como salidas de esparcimiento, ya sea a lo largo de la trayectoria de las personas o de manera contemporánea. En este sentido las personas podían alternar circuitos entre peñas y discotecas en diferentes momentos etarios, o podían participar de ambos circuitos entre fines de semana. Asimismo cabe considerar que a medida que avanzaba la década de 1980 el rock se vio envuelto en procesos de difusión de estilo (Hebdige, 2004). Esta situación generaba que los conjuntos de rock diversificaran sus circuitos y sistemas de distribución, entre los cuales se encontraban las discotecas. Esta situación generaba la confluencia de públicos rockeros que acudían de manera excepcional a un boliche bailable para apreciar los artistas que admiraban y que jóvenes asiduos a las discotecas tuvieran una experiencia como públicos de conjuntos que quizás desconocían.

Por otro lado, así como algunos jóvenes preferían las peñas en sus salidas nocturnas y podían destinar alguna noche para ir a bailar a algún boliche de moda, lo mismo sucedía con los amantes de las discotecas. Este intercambio en el espacio de divertimento, del boliche a la peña, era realizado por las mujeres, quienes, a criterio de nuestros interlocutores, vivían la experiencia como una aventura. Esos cruces de mundos y participación en diversos circuitos de divertimento también llamaron la atención de investigadores como Pujol (2011) para quien los jóvenes que transitaban los mundos de la noche circulaba la información que en las discos podían oírse músicas de calidad alternativas- y que había más oportunidades de "levante" -conquista erótica.

Además de esos saberes, en el caso de la ciudad de Córdoba, era frecuente que el personal técnico operaba en los mundos de las discotecas bailables y los recitales de rock, lo cual tendían puentes tanto profesionales como personales. Esa situación estimulaba que esos varones heterosexuales amantes del rock se sintieran atraídos por los boliches y decidieran incursionar en esos lugares buscando nuevas experiencias eróticas y estéticas. Al mismo tiempo, esa trama de discursos y prácticas hacía posible que esos sujetos percibieran que ir a las peñas fuera una aventura para mujeres.

\section{Trazar mapas y cartografías}

A lo largo de este artículo exploramos circuitos de divertimento juveniles a partir de ciertas locaciones emblemáticas de un mundo de arte en la ciudad de Córdoba durante la década de 1980. Nos preocupamos por mostrar la incidencia en estos tránsitos y consumos en la configuración de subjetividades juveniles. Aunque destacamos la delimitación de ciertas escenas que diferenciaban a los consumidores y productores, no perdimos de vista los pliegues y momentos "entre" (Turner, 1980). Si bien los interlocutores construían sus propios circuitos que habilitaban situarse en una escena específica e imaginarse con una identificación particular, se sometían a un tipo de regulación que permitía ciertas 
situaciones de contacto (Barth, 1976). Existían medios de control social para evitar tales intersecciones entre las rutas, que podían ser violentados sólo en ocasiones que eran consideradas excepcionales o de experimentación.

Advertimos que quienes gestionaban y administraban todas las locaciones comerciales que analizamos eran sujetos varones. Las mujeres no ocupaban roles destacados en los emprendimientos, pues ninguno de nuestros entrevistados mencionó alguna participación más allá de reclamos financieros de quienes fueron sus esposas por pérdidas económicas de sus locales. La administración empresarial de estos mundos de la noche fue una tecnología de género que (re)localizaba a las mujeres al ámbito doméstico (De Lauretis, 1989; Rosaldo, 1979).

A lo largo de este escrito nos preocupamos más por los espacios que por los tiempos históricos. Si bien no fue nuestra intención desatender y aplanar la variable temporal, dejamos para próximos escritos el desafío de pensar la especificidad de ciertos espacios dentro de procesos históricos mayores. Quedan muchos aspectos a indagar que nos permitan historizar cartografías urbanas de Córdoba de la década de 1980, y sobre cómo aquellos espacios tenían su efecto performativo en subjetividades juveniles.

\section{Referencias bibliográficas}

Acurso, M. B. (2016): Un mundo del folklore: Jóvenes y peñas en la ciudad de Córdoba. Trabajo Final de Maestría en Antropología- FFyH- UNC.

Alabarces, P. (1993): Entre gatos y violadores: El rock nacional en la cultura argentina (Vol. 3)- Colihue- Buenos Aires.

Becker, H. (2008): Los mundos del arte. Universidad Nacional de Quilmes- Bernal

Becker, H., \& Faulkner, R. (2011): El jazz en acción. La dinámica de los músicos sobre el escenario -Siglo XXI- Buenos Aires.

Bennett, A., \& Peterson, R. A. (2004): Music scenes: Local, translocal and virtualVanderbilt University Press- USA

Blázquez, G. (2019): Cooltura electrónica: Música, arte y subjetividades juveniles en Córdoba- Gorla- Buenos Aires

Blázquez, G., \& Peressotti, A. L. R. (2017): "La calle es un lugar-Escenas de interacción entre varones homosexuales y agentes policiales durante la década de 1980 en Córdoba (Argentina)" -Cadernos pagu- 51-Campinas

Bruno, M. S. (2015): "Un faro en la tormenta. Apuntes de un local de divertimento juvenil"- Revista Avá- 26- Misiones (págs. 199-223)

Bruno, M. S. (2019): De "Aguas de la Cañada" a "Nada en la Cañada". Análisis de un mundo de canción urbana en la Córdoba de 1980 -Tesis de Doctorado en Ciencias Antropológicas- Universidad Nacional de Córdoba.

De Lauretis, T. (1989): "Technologies of gender"- Essays on Theory, Film and FictionMacmillan Press. Londres 
Díaz, C. F. (2005): Libro de viajes y extravíos: Un recorrido por el rock argentino, 1965 1985- Narvaja- Córdoba

Díaz, C. F. (2009): Variaciones sobre el" ser nacional": Una aproximación sociodiscursiva al" folklore" argentino- Ediciones Recovecos- Córdoba

Douglas, M., \& Isherwood, B. (1990): El mundo de los bienes: Hacia una antropología del consumo- Consejo Nacional para la Cultura y las Artes- México.

Elias, N. (1987). El proceso de la civilización: Investigaciones sociogenéticas y psicogenéticas- Fondo de Cultura Económica- México

Elias, N. (1995). Sociología fundamental- Gedisa- Barcelona

Frith, S. (2014): Ritos de la interpretación: Sobre el valor de la música popular- PlanetaBuenos Aires

Geertz, C. (1987): La interpretación de las culturas- Gedisa- Barcelona

González, A. S. (2012): "Juventudes" (in)visibilizadas en la última dictadura. Estetización de la política y politización de la estética en performances oficiales de Córdoba (1980-1983)- Tesis de Doctorado en Historia- UNC.

Hebdige, D. (2004): Subcultura: El significado del estilo- Paidós- Barcelona.

Hennion, A. (2012): "Melómanos: El gusto como performance" en Hacia una sociología cultural, Buenos Aires- Benzecry, C (comp.)- Universidad Nacional de Quilmes. Buenos Aires

Lenarduzzi, V. (2012): Placeres en movimiento: Cuerpo, música y baile en la" escena electrónica"- Aidos editores- Buenos Aires.

Manzano, V. (2011): "Tiempos de contestación: Cultura del rock, masculinidad y política, 1966-1975" en Jóvenes en cuestión: Configuraciones de género y sexualidad en la cultura- Elizalde, S (coord.)- Biblos- Buenos Aires.

Manzano, V. (2018): "El psicobolche: Juventud, cultura y política en la Argentina de la década de 1980"- Izquierdas- 41 (págs. 250-275).

Perlonguer, N. (2000): El Negocio del Deseo. Prostitución Masculina en Sao PauloPaidós- Buenos Aires

Pujol, S. (2011): Historia del baile: De la milonga a la disco-Gourmet Musical- Buenos Aires.

Pujol, S. A. (2005): Rock y dictadura: Crónica de una generación (1976-1983)- EmecéBuenos Aires.

Rosaldo, M. (1979): "Mujer, cultura y sociedad: Una visión teórica"- Antropología y feminismo- España (Págs 153-181).

Schechner, R. (2000). Performance: Teoría y prácticas interculturales- Libros del RojasBuenos Aires. 
Semán, P., \& Vila, P. (1999): "Rock chabón e identidad juvenil en la Argentina neoliberal" en Los noventa. Política, sociedad y cultura en América Latina y Argentina de fin de siglo- Eudeba- Buenos Aires.

Straw, Will. (1972). Communities and scenes in popular music En The subcultures reader- Routledge- Londres

Thompson, E. P. (1995). "La economía "moral" de la multitud en la Inglaterra del siglo XVIII" en Costumbres en común- Crítica- Barcelona.

Turner, V. (1980): "Entre lo uno y lo otro: El período liminar en los "rites de passage" en La Selva de los Símbolos- Siglo XXI- Buenos Aires. 